\title{
Editorial
}

\section{Human bodies in material space: lived realities, eco-crisis and the search for transformation}

This edition of the Journal of Human Rights and the Environment is dedicated to the greatest struggle of our era - the ongoing - and increasingly urgent - struggle to confront the entrenched and growing violence (both epistemic and physical) of a global order that is rapidly entrenching both human and environmental vulnerability. 'Business as usual' is still obdurately committed to the political and juridical primacy of a fundamentally destructive capitalist ethic. What is needed - urgently now - is a fundamental worldview shift - a shift inaugurating transformed understandings and practices capable of unseating the dominant consumptive, pathological form of capitalism in the name of a renewing transformation of our deepest sense of who 'we' are as earthlings amongst other earthlings and earth systems.

In short, a literally life and death struggle is underway in our age for the very meaning of the 'human' in a world which has been destructively subjugated by the violence of the state-market complex for too long. This struggle is characterized, in significant part, by a growing effort to give fuller ethico-juridical significance to the material situations of countless human beings, non-human animals and living eco-systems placed in unprecedented danger by the irresponsible pursuit of profit and by its associated ecological legacies. The evidence of this struggle is everywhere. It takes multiple forms: scholarly engagements with vulnerability and with the radical, ambient insecurity of contemporary existence (precarity); myriad critiques of law's exclusions; calls for animal rights; rights-for-nature arguments; anti-capitalist strategies and agendas; movements to defend indigenous cultures and life-worlds; the struggles of radical lawyers and of a wide range of activist constituencies the world over to give content, meaning and force to what we can think of as forms of eco-humane justice.

The task is immense, and the field of engagement challenging. As Weston and Bollier point out in their contribution to this edition, the field is tilted firmly in favour of the commercial and statist imperatives of the global political economy. Indeed, it remains challenging to imagine any 'outside' to the hegemony of neo-liberal ecocidal discourse, governance regimes, institutional structures and regulatory mechanisms. Despite active critique on a number of fronts the values and structures of neo-liberal hegemony continue to prevail and it remains the case that our national and international legal orders are structurally committed to them and to assumptions and closures that, if their trajectory continues uninterrupted, will ultimately threaten the existence of the entire living order.

This edition of the Journal of Human Rights and the Environment grapples with the important task of considering how to create space for the materialities of human embodied existence - in a lively world of beings and systems, scenes and contexts, environments and ecosystems - to feature much more potently in our ethico-juridical deliberations and structures. This edition therefore grapples with the need to find a 
new way of seeing the multiple, rich and nuanced implications of being 'human' in an earth system in peril. It seeks out a vision which, as described in the theme for this edition, allows 'human bodies in material space' to be reimagined and reconfigured. Thus the articles contained in this edition of the Journal seek, in various ways, to reengage our understanding of both bodies and space - together - as a co-constitutive 'interanimation' (to borrow Seamon's term (this edition)) - and to explore what emerges from re-thinking environmental justice in this light. Accordingly, this edition offers four carefully written contributions as elements in a thoroughly embodimentcentred, ecologically-open reflection upon human situatedness in a vulnerable living order.

Weston and Bollier draw upon contemporary resistive energies exemplified by a variety of civil movements, new forms of activism, cyber-connection and intellectual contestation to suggest that the human species is at a 'Grotian Moment'. This moment, Weston and Bollier suggest, 'presents an unusual opening in our legal and political culture for advancing new ideas for effective and just environmental protection'. The proposition put forward by Weston and Bollier is for a 'right to environment driven by a model of ecological governance that historically has proven itself capable of such protection in practice: commons- and rights-based ecological governance'. This 'green governance' strategy is to be supported by a 'human right to commons and rights-based ecological governance' - or by the 'human right to green governance' - a right 'anchored', suggest Weston and Bollier, 'in a well defined and rich history of both substantive and procedural justice'. This new, inclusive human right, the authors argue, affirms a 'species right': 'a new category of ... right which transcends traditional categorizations, highlights the truly universal nature of the threat, and which we hold not simply as individual human beings but rather by virtue of our membership [in] the species homo sapiens ...'.

While Weston and Bollier are human rights-believers, their faith in rights-discourse does not however translate into a preference for typical top-down models of juridical ordering or for state-centred protection. The authors are quite clear that both state and market have failed to protect both humanity and the environment. Weston and Bollier turn to grass-roots driven micro-transformations energized by socially negotiated shifts based in practical experiential realities: a kind of 'vernacular law', as they put it - of great relevance for their exploration precisely because 'commons governance depends critically on the informal, socially negotiated values, principles, and rules that a given community develops. It constitutes a form of cultural ballast that gives a commons stability and self-confidence, even in the absence of formal law'.

Weston and Bollier offer, in one sense, an extended transformative meditation upon what we could view as a political phenomenology of emergence and complexity. By guiding our attention to the radical potential of complex adaptive systems and by bringing the notion of the commons into productive intimacy with such accounts and visions, Weston and Bollier offer an account open to a plethora of micro-legal and socio-political emergences born of local, place-based energies and responsive to locally felt needs and contingencies. This democratizing impulse, Weston and Bollier's analysis suggests, may produce forms of interstitial resistance to the hegemony of state-market closures, 'speaking' a range of localized and globally-salient grass-root truths to hegemonic power.

Seamon's contribution to this edition of the Journal takes the situated, experiential energies implicit in the analysis of 'commoning' offered by Weston and Bollier into an explicitly phenomenological meditation on 'human bodies in material space'. Seamon reviews certain central phenomenological concepts (including lifeworld, natural attitude, 
epoché, and the phenomenological reduction) before drawing on a rich, phenomenological discussion of 'lived body, body-subject, and environmental embodiment' to explore the living intimacy between human bodies and the material or physical 'worlds' in which they 'find themselves'. In particular, Seamon draws our attention to the phenomenological concept of place (defined as 'any environmental locus that gathers human actions, experiences, and meanings spatially'). Focusing on two major studies of urban place-making, Seamon reveals our 'environmental embodiment' in its intricate web of dynamic inter-relations, arguing that the concept of 'place justice' could mobilize further explorations of human and environmental justice.

Seamon's contribution may be read as a located account of 'place' understood as a situated matrix within, through, and around which the justice-energies animating the account offered by Weston and Bollier find a source: where else, but in the day-today, located and experiential situations of everyday embodiment-in-interaction do we form (and re-form) our political and ecological consciousness - no matter how 'global' it is in other respects?

Seamon draws in part upon the ideas of the French philosopher Maurice MerleauPonty to suggest that lived bodies 'are in an intimate relationship with the worlds in which they find themselves'. Embodiment, in this sense, has a dimension that Seamon names as environmental embodiment - a powerful sense in which bodies and places 'interanimate' each other. And although Seamon locates his examples in places in the lifeworld of the city, his reflections fully suggest myriad ways in which 'the people-place interanimation [might have meaning] for human rights and environmental justice' - which are, perhaps inescapably, 'at least partly grounded in place and environmental embodiment'.

The grounded nature of our environmental embodiment and the ethical and juridical implications of our material, living animality - our shared situatedness with other living beings and systems - forms a key element of recent scholarly attacks upon the disembodied, dislocated solipsism characterizing Cartesian epistemic mastery and the failure of the mainstream Western worldview to value the living order. The 'West' has predominantly constructed 'nature' as a storehouse from which human industry plunders the material underpinnings of both mastery and profit. This critique is central to the contribution of Weston and Bollier - and also forms a key component of De Lucia's contribution to this edition of the Journal.

De Lucia builds upon a critique of the suppositions of legal modernity to offer an analysis of two major jurisprudential attempts to reimagine the ethical and juridical significance of living materiality: Earth Jurisprudence and Law for Nature. De Lucia argues that both these legal philosophical approaches 'identify the fundamental problems of legal modernity in the Cartesian separation of the mind/subject from subjugated matter/object; the Baconian epistemology of mastery; the role of property as the central legal interpretation and apprehension of reality. Both have tried to move past these modern categories by anchoring their reasoning on a new ecological Gestalt, a new systemic and relational understanding of reality.'

De Lucia offers us a comparative critical reflection upon two distinctive candidate visions for a transformed understanding of 'what is' - two accounts offering alternative visions for a new ontology. While Earth Jurisprudence offers a vision of a community of subjects (a radically ecocentric vision of 'nature' in which nature's subjectivity is embraced and reflected in a new, ecocentric narrative placing humanity and the 'non-human' world within the same moral order), De Lucia argues that Law for Nature offers a more satisfying, albeit in some ways problematic, way forward. In preference to the ecocentrism of Earth Jurisprudence, De Lucia embraces 'the weak anthropocentric 
position' of Law for Nature, wherein humans occupy a central place which is always intrinsically delimited by "objective limits and by the inherent "demands" of natural objects'. This is emphatically not, De Lucia argues, to privilege the human, but simply to admit the inevitability of a human perspective. It is to insist, moreover, upon 'the situated participation of humans within a whole that has no privileged centre, but rather a plurality of perspectives'.

In terms of legal strategy, De Lucia argues that while Earth Jurisprudence embraces a natural rights approach, Law for Nature identifies the concept of patrimonium in order to offer an 'objective' order of ecological juridical normativity. Neither approach, however, escapes fundamental problems. Hence, De Lucia concludes by deploying the Buddhist doctrine of 'skilful means' as a way of suggesting a functional-pragmatic response highly sensitive to practical realities; a response simultaneously embracing strategically useful aspects of both approaches, while remaining attached to neither. Specifically, rights-based approaches have the advantage, for De Lucia, of reticulating with the dominant liberal suppositions of law. De Lucia, unlike Weston and Bollier, is not a committed rights-believer. He is, however, prepared to use rights-based approaches as contingent tools in an on-going conversation in which the meaning of rights may be most powerful when they are read as being as incrementalist modes of resistance to the current paradigm.

The theme of 'human bodies in material space' necessarily invokes the patterned and differentiated levels of significance, care and concern projected upon different human bodies by powerful social systems, including law. Human bodies are caught up in conscious and unconscious circulations of affective economies manifested through well-established practices of life and death, health and sickness, wealth and poverty. Environmental injustice is particularly revealing of such economies of attachment, as Davies's contribution to this edition demonstrates: environmental injustice in the US reflects a highly patterned tendency to concentrate itself upon the bodies of the African American and other non-white communities - almost without exception, economically disadvantaged communities. Davies examines the relevant jurisprudence to reveal a fundamental and problematic misalignment between the law's requirement for claimants to prove intentional (conscious) racial animus in environmental injustice cases and the best available contemporary evidence concerning the subconscious operation of racial and economic factors in human decision-making. The scientific evidence reveals the predominantly unconscious circulation of discriminatory stereotypes and assumptions implying an intensive convergence between racial and economic biases. This presents key challenges: how can subconscious bias be addressed within the spheres of environmental decision-making? How can the conscious and subconscious elements of race and economics be reconciled? The central task presented is a search for means and their oversight in practice. Davies reviews some of the suggestions made for reforms to decision-making processes - finding that the most effective mechanism 'in the multi-dimensional world of environmental decision-making [is to] improve the existing avenues for public participation ... so as to incorporate some of the improvements' suggested by various commentators. This points, inevitably, towards a greater degree of direct involvement by affected parties - a strategy that would "redress the tendency for subconscious bias to manifest itself as a lack of "outgroup" empathy'. Modes of recognition of the reality of subconscious factors - and of the failure of legal standards requiring intent or animus in order to found a claim of environmental racism or discrimination would, Davies suggests, represent progress in both environmental and distributive justice in the US, and bring US jurisprudence into closer alignment with international human rights norms. 
Finally, returning to rights-based strategies as modes of resistance, and in celebration of the power of a participatory search for an environmental justice that reflects all affected individuals and communities, this edition of the Journal of Human Rights and the Environment offers a unique platform for engagement on this theme. This edition launches a new proposed Universal Covenant Affirming a Human Right to Commons- and Rightsbased Governance of Earth's Natural Wealth and Resources, produced by Weston and Bollier as part of their ground-breaking Commons Law Project. ${ }^{1}$ The international launch by this Journal of their important initiative provides an opportunity to bring a wide range of thoughtful, critical, energetic and informed comments to bear on what is envisaged as being an essentially collective global drafting endeavour. As will be clear from Weston and Bollier's contribution to this edition, the new proposed Universal Covenant specifically invites a dynamic capture of perspectives, insights and experiences born of deeply variant situations and modes of living out the meanings of 'human bodies in material space'. In short, the international launch of this proposed Covenant invites all of us to engage in a conversation drawing upon multiple, culturally-diverse visions and languages for 'speaking' our respective 'places' in the great commons. (As noted in its first asterisk footnote, the proposed Covenant can be proactively adopted mutatis mutandis by any individual or group and/or developed through responses - hereby invited - sent directly to the Commons Law Project. ${ }^{2}$ )

Anna Grear (Co-Editor in Chief) Reader in Law, Cardiff Law School; Adjunct Associate Professor of Law, University of Waikato, New Zealand; Director, Global Network for the Study of Human Rights and the Environment (www.gnhre.org)

1. See $<$ www.commonslawproject.org $>$.

2. Please disseminate this call to your various networks. Responses should be sent to: feedback@ commonslawproject.org. 